\title{
“I FEEL LIKE A GUINEA PIG": EMOTIONAL RESPONSES TO THE ONLINE PIVOT
}

\author{
Elaine Beirne, Mairéad Nic Giolla Mhichíl, Mark Brown, Dublin City University, Ireland
}

\section{Abstract}

This paper reports on the emotional experiences of first year students as they prepared to start their higher education online because of Covid-19 public health precautions. Emotion research holds important insights for the development of pedagogical and institutional strategies to support students adapt to the increased focus on online learning both now and into the future. Students' responses to a survey embedded at the beginning of an online learning preparatory MOOC were analysed to identify (a) the anticipatory emotions they were experiencing towards online learning, and (b) what they perceived to be the sources of those emotions. Findings revealed that anxiety was the prevailing emotion, although positive emotions, such as excitement and hope, were also reported. A thematic analysis identified seven over-arching sources of those emotions as described by the students. This paper concludes by briefly discussing the implications for educators.

\section{Introduction}

The Covid-19 pandemic has propelled emotion research to the fore. The challenges faced by teachers and students in the pivot to online learning, has highlighted the need for a "pedagogy of care" in the online domain (Burke \& Larmar, 2020). To inform practice in this area, the current study investigates the emotional responses of first year students towards starting their higher education online.

The literature recognises emotion as a crucial factor that can constrain or facilitate the learning experience. Emotions are known to influence attention, self-regulation, motivation, and ultimately, learning success across different learning environments (Linnenbrink-Garcia \& Pekrun, 2011; Pekrun, Goetz, Frenzel, Barchfeld, \& Perry, 2011; Artino, 2009). According to Schutz et al. (2006), emotional experiences in education emerge from person-environment transactions. It can thus be deduced that a change in the mode of learning has the potential to elicit emotional responses among students that may influence their participation and performance. Understanding learners' emotions under 
the unique and challenging conditions of transitioning to Higher Education and an online mode of delivery, is, therefore, an important step in supporting students during and after this process.

A limited number of studies in the online domain have explored how students describe the sources of their emotional experiences. Järvenoja and Järvelä (2005) identified five main sources of emotion from students' qualitative accounts of their emotional experiences when learning using computers: (a) self, (2b) context, (c) task, (d) performance and (e) social. O'Regan (2003) found that students expressed their emotions in relation to the various aspects of an online course, such as design and organizational issues, cognitive issues, social issues, time management, and technology. Focusing on adult learners, Zembylas (2008) found that the flexibility of online learning, achievement, and the unexpected emotional nature of online communication were sources of positive emotion. Negative emotions, on the other hand, were evoked by the unknown, technology, time management issues, communication difficulties, and the struggle to obtain a work-life balance. As approaches and technologies evolve, however, more up-to-date research is needed.

In the context of the current pandemic, Espino et al. (2021) collected the emotional responses of middle and high school students towards the pivot to online learning and explored how those emotions related to the specific aspects of the online learning environment outlined in the Community of Inquiry (CoI) framework. They found that students exhibited more negative than positive emotions overall. The negative emotions were exhibited in relation to the instructional format, ability to focus, workload, and interactions with teachers, while the positive emotions were exhibited in relation to the instructional format and the flexibility of the schedule. The current study will extend this line of enquiry to first year higher education students.

\section{Methodology}

The current study was guided by the following two research questions:

- What emotions did students experience before starting college/university online?

- What were students' perceived reasons for feeling this way?

Data was collected using a cross-sectional online survey. A link to the survey was embedded in a step at the beginning of the MOOC, A Digital Edge: Essentials for the Online Learner. All responses were anonymous, and participation was optional. Ethical approval for the study was obtained from DCU's Research Ethics Committee (DCUREC/2020/150).

“A Digital Edge: Essentials for the Online Learner" was developed by Dublin City University (DCU) in collaboration with the Irish Universities Association (IUA) and 
DCU's Students Union. The aim of the MOOC was to support college and university students to adapt to the increased focus on online learning because of Covid-19. Data for the current study was collected during the first iteration of the MOOC which launched in September 2020, prior to the beginning of the first online semester for many students. In this regard, it was a prime opportunity to investigate students' prospective emotions towards learning online at college or university.

\section{Instrument}

A list of six discrete emotion states was used to collect data pertaining to participants' emotions. The list was derived from previous studies on learning-centric emotions (Beirne, 2020; Pekrun, Goetz, Frenzel, Barchfeld, \& Perry, 2011; D’Mello, 2013). Participants were directed to identify the most prominent emotion they were experiencing in response to the increased focus on online learning because of Covid-19. A further open-ended question prompted respondents to report in their own words the source of that emotion. Data pertaining to the participant's gender and whether this was their first year at university was also collected. The instrument also contained further items unrelated to the current paper.

\section{Participants}

Of the 982 MOOC participants who responded to the questionnaire, 663 of them were entering their first year of college or university. These 663 students formed the sample for this study.

\section{Quantitative Results}

Figure 1 presents the proportion of respondents who reported each emotion. Anxiety was the most frequently reported emotion, selected by nearly two thirds of the respondents (64\%). This was followed by the positive emotions of excitement (14\%) and hope (12\%). Anger and Hopelessness were rarely reported.

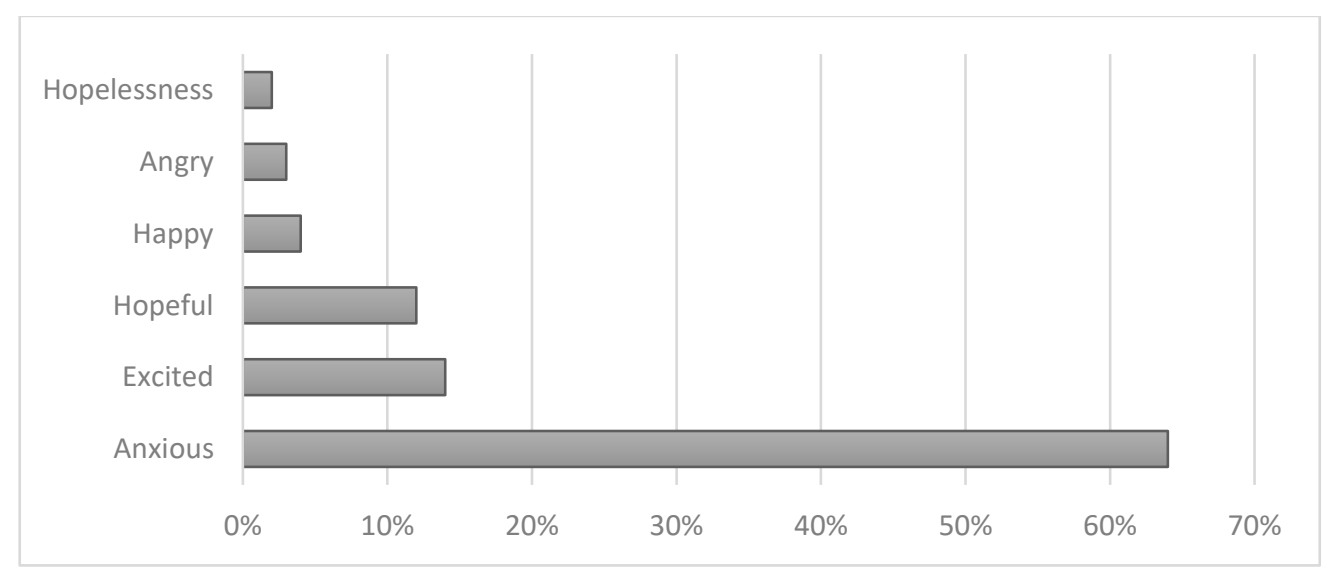

Figure 1. Emotion frequencies 


\section{Qualitative Results}

Data from the open-ended question, was analysed using thematic analysis. Braun and Clarke's (2006) six step guide was followed (see Table 1). Seven overarching themes or factors influencing learners' emotions were identified: (a) Perceptions of Ability, (b) Technology, (c) Confidence in Provider, (d) The Unknown, (e) Advantages and Disadvantages, (f) Communicating Online, and (g) The Bigger Picture (see Figure 2 for overview). Each of these themes are described below.

Table 1: Thematic Analysis Procedure

\begin{tabular}{ll}
\hline Phase & Description \\
\hline 1 & Familiarise yourself with data \\
2 & Generate initial codes \\
3 & Search for themes \\
4 & Review themes \\
5 & Define and name themes \\
6 & Produce report \\
\hline
\end{tabular}

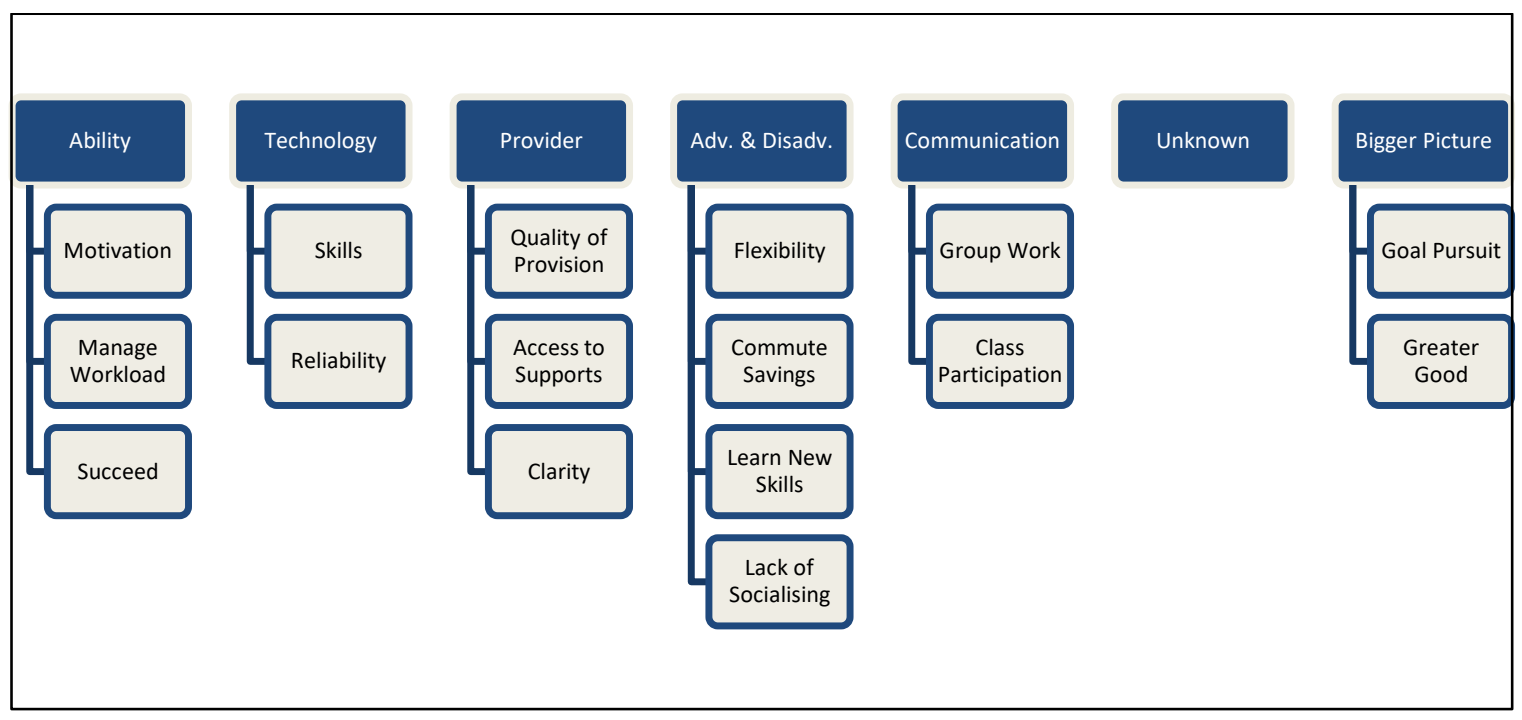

Figure 2. Themes and Subthemes

\section{Perceptions of Ability}

Varying perceptions of ability was a pervasive source of emotion. When reflecting on their emotion towards learning online, students' doubts about their own ability to learn in an online environment that was identified as a source of negative emotion. The ability to stay motivated and avoid distractions when learning from home or "off campus" was a concern voiced by students. Students also doubted their ability to manage their workload. Monitoring and deciphering the large amounts of information being provided, sometimes through a variety of different communication channels, was already becoming a prominent source of anxiety for students. Many were worried that they would miss important deadlines as a result. Anxiety, hopelessness, and anger were also brought about by students' doubts about their ability to achieve their learning goals while learning online. 
Some people reflected on a negative previous experience, while others who were new to online learning questioned their ability to adapt or held the preconception that it would be harder to learn online.

"I feel that I cannot take in information as well as being on campus in a lecture as there are too many distractions at home." (R206)

"I'm anxious to miss a class or an assignment because of the amount of mails I receive every day." (R890)

"I feel overwhelmed by the countless formats through which the same information is dispersed." (R100)

"It's nearly impossible to learn effectively online, so my mind always races on and on about how this will affect my overall experience with university." (R360)

At the same time, when students were more confident in their ability, positive emotions ensued. Some of the reasons for this confidence were positive previous online learning experiences or the expectation that the online mode of delivery would suit their learning style.

"I find it easy and comfortable to learn and study by myself." (R142)

\section{Technology}

The technology used to support online learning evoked emotions among students. Having insufficient digital skills was a source of anxiety for students who were concerned that this deficiency would impede their learning experience. Unreliable internet connections and system stability was also a source of anxiety for students. On the other hand, being comfortable around technology was a source of hope and excitement for students as they embarked on this new experience.

"I'm not great with technology and I'm nervous about falling behind, missing important deadlines etc." (R477)

"I have very poor Wi-Fi connection and online learning is very stressful." (R319)

"I've done the ECDL, have good internet and desktop/laptop so I am wellequipped to move online." (R020) 
Beirne, E., Nic Giolla Mhichíl, M., \& Brown, M.

"I Feel Like a Guinea Pig": Emotional Responses to the Online Pivot

\section{Confidence in Provider}

The confidence that students had in their college or university being able to provide the teaching and support needed in the online domain was identified as another source of emotion. Anxiety was experienced by those who questioned their access to supports or whether the quality of the teaching would be the same online. Others, who were encouraged by the universities' efforts so far reported feeling hopeful about online learning.

"Uncertainty surrounding the quality and level of learning and productivity compared to previous and future years." (R595)

“I'm worried we won't be able to get help if we need it." (R287)

"I have seen the efforts made by my university to provide a safe and enjoyable year online." (R843)

\section{The Unknown}

Learning online was a first for many of the students. This new experience was a source of both positive and negative emotion. For some, the unknown methodology of online learning was a source of apprehension and anxiety. For others, the unknown was perceived as a new challenge or adventure, which evoked excitement. It was also specified by students that these feelings, both positive and negative, were amplified by the fact not only were they starting online learning for the first time, but they were also starting university for the first time.

"University is daunting enough as it is, I feel like a guinea pig with this online learning." (R090)

"Anxious towards the idea of an unfamiliar learning style." (R082)

"This is a brand-new experience for me. I have never studied at third level and have never studied online. I cannot wait to get started." (R150)

\section{Advantages and Disadvantages}

Perceived advantages and disadvantages of starting university online evoked both positive and negative emotion, respectively. The sources of positive emotion encompassed by this theme include (a) the flexible nature of online learning and being able to learn at your own pace, (b) the opportunity to learn new skills, and (c) the monetary and time savings associated with not having to commute to campus. One or two students even mentioned that starting college in an online capacity made the transition easier. 
"I feel like I can take control of my own learning. There are less physical stresses such as travelling to campus, being in the right place at the right time. I'm also excited by the challenge of immersing myself with online learning to prepare for my future as with every year that goes by IT skills in every workplace become more and more important." (R328)

A prevalent source of negative emotion and a perceived disadvantage of online learning was the reduced opportunity to socialise with others. Making new friends was something that many students were looking forward to at university, but they felt that this would be harder online, leading to feelings of anxiety and even anger. Students also mentioned that they felt like they were missing out on a "real" university experience, which was also a source of anxiety and anger. One person in particular reported feeling angry because they felt like the entire year would be a write-off:

"I have had my time as a first year stolen from me." (R615)

"I am concerned that online learning will limit and hinder the social aspect

of college life that I was looking forward to." (R032)

\section{Communicating and Interacting Online}

The perceived difficulties associated with communicating and interacting with peers and lecturers online was a source of negative emotion for students. They worried about the practicalities of group work, as well as how effectively they would be able share their opinions or ask questions without the face-to-face connection.

"It is quite hard to truly express your ideas through a computer screen and it can be off putting not knowing your classmates in person." (R247)

"I am especially concerned about how group assignments would look like." (R714)

\section{The Bigger Picture}

When reflecting on the upcoming semester, some students' emotions went beyond the specifics of the learning context. Goal pursuit was a source of excitement for students, who mentioned that starting university in any format was better than nothing.

"I am mainly eager to start university and I am willing to learn in any manner."(R471)

The other source of emotion encompassed by this theme was the greater good. Students felt hopeful as they agreed with the precautions being taken and felt like they were playing their part to protect others against Covid-19. 
"I am hopeful that by learning online I can help keep those around me safe." (R278)

\section{Conclusions}

This study examined the emotional experiences of first year higher education students as they prepared to start learning online. The findings contribute to an increased understanding of emotions associated with online and distance learning. As can be expected from the unprecedented nature of the experience, anxiety was by far the most common emotion experienced by the students. However, the reasons behind students' emotions were more wide-ranging. Many of the sources of emotion identified are consistent with previous literature. These include technology, the unknown, workload and time-management, communication difficulties, the ability to focus, and the flexibility of online learning (Espino et al. 2021; Hilliard, Kear, Donelan, \& Heaney, 2020; Järvenoja \& Järvelä, 2005; O’Regan, 2003; Zembylas, 2008). Other sources identified, such as the socialising concerns and confidence in the provider, were more context-specific but could be relevant to those undertaking full-time online degrees irrespective of the pandemic.

The findings of this research hold important insights for institutional leadership and educators who endeavour to support students in the transition to online learning, both in crisis situations, such as the on-going Covid-19 pandemic, and beyond. Some of the takeaways might include:

- The importance of considering the wide spectrum of digital and other online learning-related competences in the student body. Additional supports may be needed for those who do not have the necessary skills.

- The value of social interactions to students. Social time could be incorporated into live lectures or facilitated outside teaching hours.

- The value of fully leveraging the flexibility afforded by online and distance provision. Flexibility can be incorporated into both instruction and assessment.

- The need to develop and share a clear and consistent communication strategy with students.

In conclusion, the current study captures the emotions expressed by students towards online learning in advance of that experience. A follow-up study after a sustained period of online learning would provide comparative insights to identify how students' emotions change over time as well as the factors contributing to such changes. 


\section{References}

Artino, A. R. (2009). Think, feel, act: Motivational and emotional influences on military students' online academic success. Journal of Computing in Higher Education, 21(2), 146-166.

Beirne, E. (2020). What a feeling! A multistage, multimethod Investigation of emotions and their antecedents in an Irish language MOOC (PhD thesis). Dublin City University.

Burke, K., \& Larmar, S. (2020). Acknowledging another face in the virtual crowd: Reimagining the online experience in higher education through an online pedagogy of care. Journal of Further and Higher Education, 1-15.

D’Mello, S. (2013). A selective meta-analysis on the relative incidence of discrete affective states during learning with technology. Journal of Educational Psychology, 105(4), 1082-1099.

Espino, D. P., Wright, T., Brown, V. M., Mbasu, Z., Sweeney, M., \& Lee, S. B. (2021). Student Emotions in the Shift to Online Learning during the COVID-19 Pandemic. Proceedings of the International Conference on Quantitative Ethnography, 334-347. Springer, Cham.

Hilliard, J., Kear, K., Donelan, H., \& Heaney, C. (2020). Students' experiences of anxiety in an assessed, online, collaborative project. Computers \& Education, 143, 103675.

Järvenoja, H., \& Järvelä, S. (2005). How Students Describe the Sources of Their Emotional and Motivational Experiences during the Learning Process: A Qualitative Approach. Learning and Instruction, 15(5), 465-480.

O’Regan, K. (2003). Emotion and e-learning. Journal of Asynchronous Learning Networks, $7(3), 78-92$

Pekrun, R., Goetz, T., Frenzel, A. C., Barchfeld, P., \& Perry, R. P. (2011). Measuring emotions in students' learning and performance: The Achievement Emotions Questionnaire (AEQ). Contemporary Educational Psychology, 36(1), 36-48.

Schutz, P. A., Hong, J. Y., Cross, D. I., \& Osbon, J. N. (2006). Reflections on investigating emotion in educational activity settings. Educational Psychology Review, 18(4), 343360. doi:10.1007/ s10648-006-9030-3

Zembylas, M. (2008). Adult learners' emotions in online learning. Distance Education, 29(1), 71-87. 